\title{
Retos actuales en la protección jurídica de la discapacidad
}

\section{Current challenges in the legal disability protection}

\author{
Inmaculada Vivas Tesón
}

\section{Resumen}

Los tratados internacionales han evaluado muy visible a las personas con discapacidad, en especial la Convención de las Naciones Unidas - ONU sobre los Derechos de las Personas con Discapacidad. Signatario de este tratado internacional, España realiza una serie de cambios legislativos con el fin de adaptar la ley a las disposiciones del Convenio. A través de la investigación bibliográfica, el objetivo es analizar la legislación española después de la ratificación de la Convención de las Naciones Unidas, en concreto el Real Decreto 1/2013 que regula el marco jurídico de los derechos de las personas con discapacidad. Se concluye que, a pesar de los avances legales del Decreto, en particular en relación con la autonomía y la libertad de las personas con discapacidad, todavía hay ambigüedades y contradicciones de esta ley en relación con la legislación española.

Palabras claves: ONU convección sobre los derechos de las personas con discapacidad. Real Decreto Legislativo 1/2013. Discapacidad. Protección jurídica.

Doutora em Direito Civil. Profesora titular de Derecho civil da Universidade de Sevilha. Sevilha Andaluzia - Espanha. Email: ivivas@us.es 


\section{Resumo}

Os tratados internacionais aferiram grande visibilidade às pessoas com deficiência, destacando-se a Convenção da Organização das Nações Unidas - ONU sobre os Direitos das Pessoas com Deficiência. Signatária desse tratado internacional, a Espanha realiza uma série de alterações legislativas com o intuito de adaptar o direito interno aos preceitos da Convenção. Por meio de pesquisa bibliográfica, objetiva-se analisar o direito espanhol após a ratificação da Convenção da ONU, especificamente o Real Decreto 1/2013 que, regula o quadro legislativo dos direitos das pessoas com deficiência. Conclui-se que, apesar dos avanços jurídicos do Decreto, especialmente em relação à autonomia e à liberdade da pessoa com deficiência, há ainda ambiguidades e contradições dessa lei em relação ao ordenamento jurídico espanhol.

Palavras-chave: Conveção da ONU sobre os direitos das pessoas com deficiência. Real Decreto Legislativo 1/2013. Incapacidade. Proteção jurídica.

\section{Abstract}

International treaties have assessed highly visible to people with disabilities, especially the Convention of the United Nations - UN on the Rights of Persons with Disabilities. Signatory to this international treaty, Spain performs a number of legislative changes in order to adapt the law to the Convention's provisions. Through bibliographical research, the objective is to analyze the Spanish law after ratification of the UN Convention, specifically Royal Decree 1/2013 which regulates the legal framework of the rights of persons with disabilities. It concludes that, despite legal advances of the Decree, particularly in relation to the autonomy and liberty of people with disabilities, there are still ambiguities and contradictions of this law in relation to Spanish law.

Keywords: UN Convection on the rights of persons with disabilities. Royal Legislative Decree 1/2013. Inability. Legal protection. 


\title{
Introducción
}

De repente, como si fuera por arte de magia, las personas con discapacidad $^{1}$, huérfanas durante tanto tiempo de protección jurídica, se han hecho visibles a raíz de la reciente "humanización" de los legisladores internacionales, europeos y nacionales.

Y ello, a pesar de que, aproximadamente, tales personas representan un $15 \%$ de la población mundial, más de mil millones de personas, cifra ésta en progresivo aumento, debido, principalmente, al envejecimiento demográfico y consiguiente incremento de la longevidad y al aumento mundial de enfermedades crónicas tales como la diabetes, las enfermedades cardiovasculares, el cáncer y los trastornos de la salud mental, según indica la Organización Mundial de la Salud (OMS).

\begin{abstract}
Nuestro legislador, quien ha experimentado una evolución terminológica en la materia, se ha percatado de la enorme importancia de un cuidadoso uso del lenguaje en el entorno de la discapacidad y, así, ya la Ley 41/2003, de 18 de noviembre, lleva por rúbrica "Protección patrimonial de las personas con discapacidad" (no "discapacitadas"), estableciendo en la Disposición Adicional $8^{a}$ de la Ley 39/2006, de 14 de diciembre de 2006, de Promoción de la Autonomía Personal y Atención a las personas en situación de Dependencia, que las referencias contenidas en los textos normativos a los "minusválidos" y a las "personas con minusvalía", se entenderán realizadas a "personas con discapacidad", y que dicho término será el utilizado para denominarlas en las disposiciones normativas elaboradas por las Administraciones Públicas.

Tal ha sido el término empleado en la Convención de Naciones Unidas sobre los Derechos de las Personas con Discapacidad, hecha en Nueva York el 13 de diciembre de 2006, en cuyo Preámbulo se reconoce que "e) la discapacidad es un concepto que evoluciona y que resulta de la interacción entre las personas con deficiencias y las barreras debidas a la actitud y al entorno que evitan su participación plena y efectiva en la sociedad, en igualdad de condiciones con las demás".
\end{abstract}

De este modo, en un proceso de adecuación terminológica y conceptual de las normas reguladoras de la discapacidad, conforme al mandato de la citada Disp. Ad. $8^{\text {a }}$ y a la Clasificación Internacional del Funcionamiento, de la Discapacidad y de la Salud (CIF-2001) de la Organización Mundial de la Salud (OMS), el RD. 1856/2009, de 4 de diciembre, de procedimiento para el reconocimiento, declaración y calificación del grado de discapacidad, y por el que se modifica el RD. 1971/1999, de 23 de diciembre, sustituye el término "minusvalía" por el de "discapacidad", y las referencias que en el RD. 1971/1999 se realizaban hasta ahora a "grado de discapacidad" se sustituyen por "grado de las limitaciones en la actividad". Por consiguiente, debemos desterrar, por completo, de nuestro lenguaje el término peyorativo "minusvalía". Repárese en que el art. 49 de la Constitución Española (en adelante, CE) aún sigue conservando el término "disminuidos": "los poderes públicos realizarán una política de previsión, tratamiento, rehabilitación e integración de los disminuidos físicos, sensoriales y psíquicos, a los que prestarán la atención especializada que requieran y los ampararán especialmente para el disfrute de los derechos que este Título otorga a todos los ciudadanos". 
En el año 2003, declarado "Año Europeo de las personas con discapacidad"2, las estadísticas (según la oficina Eurostat) indicaban que 38 millones de europeos padecían algún tipo de discapacidad, bien sea física, psíquica o sensorial, esto es, un $14,5 \%$ de la población total de la UE entre 16 y 64 años $^{3}$, distinguiendo que un $10 \%$ son personas con discapacidad moderada y un $4,5 \%$ con discapacidad severa. Por sexos, la población femenina con discapacidad supera a la masculina.

En nuestro país, alrededor de un $8,5 \%$ de la población, esto es, más de 3,8 millones de personas residentes en hogares españoles, por sexo, más de 2,30 millones de mujeres frente a 1,55 de hombres, según datos extraídos de la Encuesta de Discapacidad, Autonomía personal y situaciones de Dependencia (conocida como EDAD) del Instituto Nacional de Estadística, publicada en noviembre de 2008 (hace ya,

Bajo esta misma óptica revisora de la terminología, el legislador, en la Disposición Final $1^{\text {a }}$ de la Ley 1/2009, de 25 de marzo, de reforma de la Ley de 8 de junio de 1957, sobre el Registro Civil, en materia de incapacitaciones, cargos tutelares y administradores de patrimonios protegidos, y de la LPPD, ha asumido el compromiso de reformar los procedimientos de incapacitación judicial, que pasarán a denominarse "procedimientos de modificación de la capacidad de obrar", nomenclatura, expresada en términos positivos, mucho más respetuosa con la persona y su derecho al ejercicio de su capacidad de obrar, el cual implica autonomía e independencia individual, así como libertad de tomar sus propias decisiones. Ha de tenerse en cuenta que la Convención ONU utiliza el término "capacidad jurídica", no "capacidad de obrar".

En la misma línea, el art. 25 de la Orgánica 10/1995, de 23 de noviembre, del Código Penal, ha recibido, recientemente, nueva redacción por la Ley Orgánica 1/2015, de 30 de marzo, con el fin de adecuar las normas del Código Penal a la Convención ONU, pasando a tener el siguiente tenor literal: "A los efectos de este Código se entiende por discapacidad aquella situación en que se encuentra una persona con deficiencias físicas, mentales, intelectuales o sensoriales de carácter permanente que, al interactuar con diversas barreras, puedan limitar o impedir su participación plena y efectiva en la sociedad, en igualdad de condiciones con las demás.

Asimismo a los efectos de este Código, se entenderá por persona con discapacidad necesitada de especial protección a aquella persona con discapacidad que, tenga o no judicialmente modificada su capacidad de obrar, requiera de asistencia o apoyo para el ejercicio de su capacidad jurídica y para la toma de decisiones respecto de su persona, de sus derechos o intereses a causa de sus deficiencias intelectuales o mentales de carácter permanente". De este modo, como explica en la Exposición de Motivos de la Ley Orgánica 1/2015, se modifica el art. 25 del CP para actualizar la terminología empleada y ofrecer una definición más precisa de las personas que constituyen objeto de una especial protección penal.

2 Decisión del Consejo, de 3 de diciembre de 2001, publicado en el DOUE, Serie L, núm. 335, de 19 de diciembre de 2001.

3 A título de curiosidad, Finlandia es el país con mayor número de personas con discapacidad, con un $23 \%$ de su población, mientras que Bélgica, Irlanda e Italia (alrededor de un $7,8 \%$ ) son los países con un menor porcentaje. 
por tanto, algunos años) (INSTITUTO NACIONAL DE ESTADÍSTICA, online, 2008), son personas con discapacidad ${ }^{4}$.

\section{UN NUEVO ENFOQUE DEL DERECHO ESPAÑOLA PARTIR DE LA CONVENCIÓN ONU SOBRE LOS DERECHOS DE LAS PERSONAS CON DISCAPACIDAD}

Llama poderosamente la atención la casi total ausencia de específicos Tratados internacionales en materia de protección de los derechos humanos de las personas con discapacidad, pese a ser uno de los grupos particularmente vulnerables, si no el que más (si lo consideramos en relación a los otros grupos, en la medida en que una mujer, un niño, un indígena, etc., es aún más vulnerable si tiene una discapacidad, de manera que queda más expuesto a que no sean respetados sus derechos humanos), hasta 2006, en el marco de las Naciones Unidas.

Los Tratados generales o relativos a las otras categorías de personas vulnerables, bien se limitan a reconocer el derecho a la no discriminación, o bien incluyen sólo, marginalmente, algunas referencias a las personas con discapacidad. Así, destacamos, entre los Instrumentos Internacionales, los arts. $1^{5}, 3^{6}, 22^{7}$ y $25.1^{8}$ de la Declaración Universal

$4 \quad$ Es de destacar que la Asamblea General de las Naciones Unidas, especialmente en sus resoluciones $63 / 150$ y 64/131, ha destacado la importancia de mejorar los datos y las estadísticas relativos a la discapacidad, en consonancia con la legislación nacional, de manera que sean comparables tanto en el plano internacional como en el interno a los efectos de diseñar, planificar y evaluar políticas desde la perspectiva de las personas con discapacidad; y ha instado a los Gobiernos a que cooperen y hagan uso de la asistencia técnica de la Statistic Division (División de Estadística) del Departamento de Asuntos Económicos y Sociales de la Secretaría.

5 Art. 1: "Todos los seres humanos nacen libres e iguales en dignidad y derechos y, dotados como están de razón y conciencia, deben comportarse fraternalmente los unos con los otros".

6 Art. 3: "Todo individuo tiene derecho a la vida, a la libertad y a la seguridad de su persona".

7 Art. 22: "Toda persona, como miembro de la sociedad, tiene derecho a la seguridad social, y a obtener, mediante el esfuerzo nacional y la cooperación internacional, habida cuenta de la organización y los recursos de cada Estado, la satisfacción de los derechos económicos, sociales y culturales, indispensables a su dignidad y al libre desarrollo de su personalidad".

$8 \quad$ Art. 25.1: "1. Toda persona tiene derecho a un nivel de vida adecuado que le asegure, así como a su familia, la salud y el bienestar, y en especial la alimentación, el vestido, la vivienda, la asistencia médica y los servicios sociales necesarios; tiene asimismo derecho a los seguros en caso de desempleo, enfermedad, invalidez, viudez, vejez u otros casos de pérdida de sus medios de subsistencia por circunstancias independientes de su voluntad". 
de Derechos Humanos, el art. $2^{9}$ del Pacto Internacional de Derechos Civiles y Políticos y los arts. $9^{10}, 11.1^{11}$ y $12.1^{12}$ del Pacto Internacional de Derechos Económicos, Sociales y Culturales.

La Asamblea General de las Naciones Unidas proclamó, basándose en la Carta Internacional de Derechos Humanos, los primeros documentos específicos relacionados con la discapacidad, entre otros $^{13}$ : la Declaración de los Derechos del Retrasado Mental mediante Resolución 2856 (XXVI) de 20 de diciembre de 1971, la Declaración de los Derechos de los Impedidos mediante la Resolución 3447 (XXX) de 9 de diciembre de 1975, los Principios para la protección de los enfermos mentales y el mejoramiento de la atención de la salud mental mediante la Resolución 46/199 de 17 de diciembre de 1991, las Normas Uniformes sobre la Igualdad de Oportunidades para las Personas con Discapacidad aprobadas mediante Resolución 46/96, de 20 de diciembre de 1993 y la Resolución 1998/31 de la Comisión de Derechos Humanos: Los derechos humanos y las personas con discapacidad.

Podría afirmarse, sin temor a errar, que los trabajos que viene la ONU realizando, sin cesar, desde los años 70, representan las acciones

$9 \quad$ Art. 2: "1. Cada uno de los Estados Partes en el presente Pacto se compromete a respetar y a garantizar a todos los individuos que se encuentren en su territorio y estén sujetos a su jurisdicción los derechos reconocidos en el presente Pacto, sin distinción alguna de raza, color, sexo, idioma, religión, opinión política o de otra índole, origen nacional o social, posición económica, nacimiento o cualquier otra condición social.

2. Cada Estado Parte se compromete a adoptar, con arreglo a sus procedimientos constitucionales y a las disposiciones del presente Pacto, las medidas oportunas para dictar las disposiciones legislativas o de otro carácter que fueren necesarias para hacer efectivos los derechos reconocidos en el presente Pacto y que no estuviesen ya garantizados por disposiciones legislativas o de otro carácter".

10 Art. 9: "El derecho de toda persona a la seguridad social, incluso al seguro social".

11 Art. 11.1: "... el derecho de toda persona a un nivel de vida adecuado para sí y su familia, incluso alimentación, vestido y vivienda adecuados, y a una mejora continua de las condiciones de existencia. Los Estados Partes tomarán medidas apropiadas para asegurar la efectividad de este derecho, reconociendo a este efecto la importancia esencial de la cooperación internacional fundada en el libre consentimiento".

12 Art. 12.1: "El derecho de toda persona al disfrute del más alto nivel posible de salud física y mental".

13 Una cronología completa puede consultarse en y todos los documentos recientes de la ONU sobre discapacidad en 
más importantes llevadas a cabo por una organización internacional en materia de discapacidad, lo que ha permitido una toma de conciencia y compromiso internacional acerca de los derechos humanos de las personas privadas de autonomía, las cuales, durante mucho tiempo, han permanecido "invisibles".

En este sentido, hito normativo ( $\mathrm{y}$, añadiríamos, sociocultural) de enorme repercusión que, a nuestro juicio, supone un punto de inflexión al marcar un antes y un después, lo es la Convención ONU sobre los Derechos de las Personas con Discapacidad hecha en Nueva York el 13 de diciembre de 2006 (y su Protocolo Facultativo) ${ }^{14}$, la cual ha venido a cambiar radicalmente el panorama jurídico en esta materia, no por establecer nuevos derechos humanos a los ya proclamados en otros Acuerdos Internacionales, que no los establece, pues, por su condición de universales, se predican de todos los hombres y mujeres sin excepción, sino por introducir un nuevo concepto de discapacidad y contemplar medidas de no discriminación y de acción positiva para lograr la efectiva tutela de las personas con discapacidad ${ }^{15}$.

14 Acerca de la Convención, vid., entre otros, CABRA DE LUNA, M. A./BARIFFI, F./PALACIOS, A.: Derechos humanos de las personas con discapacidad: la Convención Internacional de las Naciones Unidas, Madrid, 2007; RUBIO TORRANO, E.: "Convención sobre los derechos de las personas con discapacidad", en Aranzadi Civil, 2008, núm. 14, págs. 11-13 e INSTITUTO DE DERECHOS HUMANOS "BARTOLOMÉ DE LAS CASAS": La Convención Internacional sobre los derechos de las personas con discapacidad y su impacto en el Ordenamiento Jurídico español, Madrid, 2008.

15 Los principios generales de la Convención, recogidos en su art. 3, son: el respeto a la dignidad inherente, la autonomía individual, incluida la libertad de tomar las propias decisiones, y la independencia de las personas; la no discriminación; la participación e inclusión plenas y efectivas en la sociedad; el respeto por la diferencia y la aceptación de las personas con discapacidad como parte de la diversidad y la condición humanas; la igualdad de oportunidades; la accesibilidad; la igualdad entre hombre y mujer y el respeto a la evolución de las facultades de los niños y de las niñas con discapacidad y de su derecho a preservar su identidad, mujeres y niños que son dos subgrupos aún más vulnerables dentro del grupo de personas con discapacidad. Ciertamente, tales principios ya estaban recogidos en los enunciados de la Ley 51/2003, de 2 de diciembre, de igualdad de oportunidades, no discriminación y accesibilidad universal de las personas con discapacidad (más conocida como LIONDAU), sin embargo, la Convención supone un cambio en el concepto de discapacidad, puesto que pasa a considerarla como una cuestión de derechos humanos y no como una preocupación en materia de bienestar social.En este sentido, MÁRQUEZ CARRASCO, C.: Logros y desafíos en el 60 aniversario de la Declaración Universal de Derechos Humanos, Deusto (Bilbao), 2008, p. 60, para quien "el propósito de la Convención es promover, proteger y garantizar el disfrute pleno y por igual del conjunto de los derechos humanos 
Fuera del ámbito de Naciones Unidas, destaca, dentro de los sistemas regionales de protección de los derechos humanos, los arts. $11.1^{16}$ y $24^{17}$ de la Convención Americana sobre Derechos Humanos, la Convención Interamericana para la eliminación de todas las formas de discriminación contra las personas con discapacidad aprobada por la Organización de los Estados Americanos, en la primera sesión plenaria, celebrada el 7 de junio de 1999 (OEA/Ser. P AG/RES. 1608 (XXIX-O/99), los arts. $16^{18}$ y $18.4^{19}$ de la Carta Africana sobre Derechos Humanos y de los Pueblos y el art. $30^{20}$ de la Carta árabe de los derechos humanos.

Por su parte, la Unión Europea ha demostrado un alto nivel de conciencia por el respeto a los derechos humanos de las personas con discapacidad, muy especialmente, a partir del año 2003, que, como antes se indicó, fue declarado "Año Europeo de las Personas con Discapacidad".

En el art. 14 del Convenio Europeo para la Protección de los Derechos Humanos y las Libertades Fundamentales la prohibición de la discriminación no contiene referencia directa a la discapacidad y la única alusión que se hace a una determinada clase de discapacidad

de las personas con discapacidad. Cubre una serie de ámbitos fundamentales tales como la accesibilidad, la libertad de movimiento, la salud, la educación, el empleo, la habilitación y la rehabilitación, la participación en la vida política, y la igualdad y no discriminación. La Convención marca un cambio en el concepto de discapacidad, pasando de una preocupación en materia de bienestar social a una cuestión de derechos humanos, que reconoce que las barreras y los prejuicios de la sociedad constituyen en sí mismos una discapacidad. Esta Convención no crea nuevos derechos, lo que hace es expresar los derechos existentes en una forma que atiende a las necesidades y la situación de las personas con discapacidad".

16 Art. 11.1: "Toda persona tiene derecho al respeto de su honra y al reconocimiento de su dignidad".

17 Art. 24: "Todas las personas son iguales ante la ley. En consecuencia, tienen derecho, sin discriminación, a igual protección de la ley".

18 Art. 16: "1. Todo individuo tendrá derecho a disfrutar del mejor estado físico y mental posible.

2. Los Estados firmantes de la presente Carta tomarán las medidas necesarias para proteger la salud de su pueblo y asegurarse de que reciben asistencia médica cuando están enfermos".

19 Art. 18.4: "Los ancianos y los minusválidos también tendrán derecho a medidas especiales de protección adecuadas a sus necesidades físicas o morales".

20 Art. 30: "El Estado garantiza el derecho de todo ciudadano a trabajar a fin de asegurar para sí mismo un nivel de vida que cumple con los requisitos básicos de la vida. El Estado también garantiza el derecho de todo ciudadano a la seguridad social integral". 
(los enajenados mentales) es la que realiza el art. 5.1.e) que los agrupa junto a los enfermos contagiosos, los alcohólicos, los toxicómanos y los vagabundos a efectos de reconocer, como excepción al derecho a la libertad, la posibilidad de que estas personas sean detenidas "regularmente", esto es, conforme a la ley y con las garantías previstas en el apartado 2 de dicho precepto.

Entre las posteriores disposiciones, en el ámbito europeo, acerca de la discapacidad ${ }^{21}$, mención especial precisa un instrumento normativo de gran trascendencia en la materia que nos ocupa, el Convenio Europeo sobre los derechos humanos y la biomedicina: Convenio para la protección de los derechos humanos y la dignidad del ser humano con respecto a las aplicaciones de la Biología y la Medicina (conocido como

21 Podemos destacar, entre otras: la Resolución del Consejo de 21 de enero de 1974 relativa a un Programa de acción social; la Resolución del Consejo de 27 de junio de 1974 relativa al establecimiento del primer Programa de acción comunitaria para la adaptación profesional de los minusválidos; la Resolución del Consejo de 13 de diciembre de 1976 sobre empleo de minusválidos jóvenes; la Recomendación del Consejo de 24 de julio de 1986 sobre el empleo de personas minusválidas; la Resolución del Parlamento Europeo de 11 de mayo de 1981 sobre integración económica, social y profesional de las personas minusválidas; la Resolución del Consejo de 21 de diciembre de 1981 sobre integración social de los minusválidos; la Decisión del Consejo de 18 de abril de 1988 por la que se adopta un Segundo Programa de Acción de la Comunidad a favor de los minusválidos (HELIOS), continuando así lo iniciado el 27 de junio de 1974; la Resolución del Parlamento Europeo, de 17 de junio de 1988 sobre lenguajes gestuales para sordos; Resolución de 31 de mayo de 1990, del Consejo y de los Ministros de Educación reunidos en su seno, relativa a la integración de los niños y los jóvenes minusválidos en los sistemas educativos ordinarios; Resolución del Consejo de la Unión europea y representantes de los gobiernos de los Estados Miembros reunidos en el Consejo el 20 de diciembre de 1996, relativa a la igualdad de oportunidades para las personas con discapacidad; Resolución del Consejo de 17 de junio de 1999, relativa al a igualdad de oportunidades laborales de las personas con minusvalías; Comunicación del a Comisión al Consejo, al Parlamento Europeo, al Comité Económico y Social y al Comité de las Regiones, de 12 de mayo de 2000, "Hacia una Europa sin barreras para las personas con discapacidad"; Directiva (2000/78/CE) del Consejo del 27 de noviembre de 2000 que establece un marco general para el tratamiento igualitario en el empleo y la ocupación; Decisión del Consejo (2000/750/CE) sobre la creación de un programa de acción comunitario que luche contra la discriminación (2001-2006); Decisión del Consejo (2001/903/ CE) del 3 de diciembre de 2001 relativa al Año Europeo de Personas con Discapacidad 2003; Comunicación de la Comisión al Consejo COM (2003) 650 final, al Parlamento Europeo, al Comité Económico y Social Europeo y al Comité de las Regiones, de 30 de octubre de 2003, relativa a la Igualdad de oportunidades para las personas con discapacidad: un plan de acción europeo; Resolución del Consejo de la Unión Europea y los Representantes de los Gobiernos de los Estados miembros reunidos en el Consejo el 17 de marzo de 2008 relativa a la situación de las personas con discapacidad en la Unión Europea. 
"Convenio de Oviedo"), de 4 de abril de 1997 (aprobado y ratificado por España el 23 de julio de 1999, con entrada en vigor el 1 de enero de 2000), así como los arts. $20^{22}, 21^{23}, 25^{24}, 26^{25}, 34^{26}$ y $35^{27}$ de la Carta de Derechos Fundamentales de la Unión Europea, que constituye el acervo europeo común en materia de Derechos Fundamentales.

Es preciso destacar que la Unión Europea ha ratificado la Convención ONU sobre los derechos de las personas con discapacidad, convirtiéndose, de este modo, en la primera organización intergubernamental en firmar un Tratado Internacional de derechos humanos.

Descrito el panorama normativo en torno a la discapacidad, resulta obligado detenernos en la Convención ONU sobre los Derechos de las Personas con Discapacidad, hecha en Nueva York en el año 2006, el

22 Art. 20: "Todas las personas son iguales ante la ley".

23 Art. 21: "1. Se prohíbe toda discriminación, y en particular la ejercida por razón de sexo, raza, color, orígenes étnicos o sociales, características genéticas, lengua, religión o convicciones, opiniones políticas o de cualquier otro tipo, pertenencia a una minoría nacional, patrimonio, nacimiento, discapacidad, edad u orientación sexual.

2. Se prohíbe toda discriminación por razón de nacionalidad en el ámbito de aplicación del Tratado constitutivo de la Comunidad Europea y del Tratado de la Unión Europea y sin perjuicio de las disposiciones particulares de dichos Tratados".

24 Art. 25: "La Unión reconoce y respeta el derecho de las personas mayores a llevar una vida digna e independiente y a participar en la vida social y cultural".

25 Art. 26: "...el derecho de las personas discapacitadas a beneficiarse de medidas que garanticen su autonomía, su integración social y profesional y su participación en la vida de la comunidad".

26 Art. 34: "1. La Unión reconoce y respeta el derecho de acceso a las prestaciones de seguridad social y a los servicios sociales que garantizan una protección en casos como la maternidad, la enfermedad, los accidentes laborales, la dependencia o la vejez, así como en caso de pérdida de empleo, según las modalidades establecidas por el Derecho comunitario y las legislaciones y prácticas nacionales.

2. Toda persona que resida y se desplace legalmente dentro de la Unión tiene derecho a las prestaciones de seguridad social y a las ventajas sociales con arreglo al Derecho comunitario y a las legislaciones y prácticas nacionales.

3. Con el fin de combatir la exclusión social y la pobreza, la Unión reconoce y respeta el derecho a una ayuda social y a una ayuda de vivienda para garantizar una existencia digna a todos aquellos que no dispongan de recursos suficientes, según las modalidades establecidas por el Derecho comunitario y las legislaciones y prácticas nacionales".

27 Art. 35: "Toda persona tiene derecho a la prevención sanitaria y a beneficiarse de la atención sanitaria en las condiciones establecidas por las legislaciones y prácticas nacionales. Al definirse y ejecutarse todas las políticas y acciones de la Unión se garantizará un alto nivel de protección de la salud humana". 
primer gran Tratado del sistema universal de derechos humanos del Siglo XXI, cuyos principios cardinales son "in dubio pro capacitas" e "intervención mínima"28.

El marco legal establecido por el art. 12 del Tratado Internacional contempla un cambio en el modelo a adoptar a la hora de regular la capacidad jurídica de las personas con discapacidad, especialmente, en aquellas situaciones en las cuales puede resultar necesario algún tipo de intervención de terceros: mientras que el sistema tradicional tiende hacia un modelo de "sustitución" en la toma de decisiones, el modelo de derechos humanos basado en la dignidad intrínseca de todas las personas, sobre el cual gira la Convención, aboga por un modelo de "apoyo" en la toma de decisiones.

La Convención hace hincapié en la enorme importancia que reviste para las personas con discapacidad el respeto a su autonomía individual, incluida la libertad de tomar decisiones, su voluntad, sus preferencias (Preámbulo, letra n y arts. 3 y 12.4).

Al respecto, permítasenos subrayar que la especial trascendencia de dicho Tratado Internacional no radica en su contenido innovador, que no lo es, sino en que, a diferencia de otras Declaraciones de derechos y principios generales de la ONU (como la Declaración de los Derechos del Retrasado Mental y la Declaración de los derechos de los Impedidos o las Normas Uniformes para la Igualdad de Oportunidades y la no Discriminación), inspiradoras de leyes y políticas de muchos países pero carentes de fuerza normativa, la Convención ONU sobre los Derechos de las Personas con Discapacidad es un instrumento jurídico de carácter obligatorio.

28 V. Conclusiones de las Jornadas de Fiscales Especializados en la Protección de las Personas con Discapacidad y Tutelas del 19 y 20 de Octubre de 2009 (MINISTERIO FISCAL, online, 2009). La efectiva aplicación de la Convención de Naciones Unidas sobre los derechos de las personas con discapacidad y sus efectos en el Derecho interno (GANZENMÜLLER ROIG, online, 2009) (dir.). 
Así las cosas, los Estados que han ratificado o se han adherido a la Convención ${ }^{29}$ se comprometen a adoptar nuevas leyes nacionales, y derogar o modificar las ya existentes con el fin de promover la plena y efectiva integración de las personas con discapacidad en los diferentes ámbitos de la sociedad, garantizando sus derechos y su plena ciudadanía.

En este sentido, la ratificación, por parte de España, de la Convención $\mathrm{ONU}^{30}$ y de su Protocolo Facultativo ${ }^{31}$ y su recepción por el Ordenamiento español, del cual ha pasado a formar parte en virtud de lo dispuesto en los arts. 96.1 CE y 1.5 del Código civil (en adelante, C.c.) obliga a proceder a una íntegra revisión legislativa que logre que nuestro Derecho interno se corresponda, exactamente, con los principios, valores y mandatos proclamados en dicho Tratado internacional, debiendo, por consiguiente, adaptar nuestra legislación al reconocimiento y garantía de los derechos de las personas con discapacidad, muy especialmente, el de igualdad.

Actualmente, estamos inmersos en dicho proceso de reformulación y, en su caso, supresión de normas vigentes discriminatorias. Ejemplo de ello lo son la Ley 26/2011, de 1 de agosto y el Real Decreto 1276/2011, de 16 de septiembre, de adaptación normativa a la Convención Internacional sobre los Derechos de las Personas con Discapacidad.

Dicho proceso de adaptación de nuestro Ordenamiento Jurídico a la Convención ONU está aún inacabado. Estamos a la espera de una anunciada reforma del procedimiento de incapacitación judicial ${ }^{32}$,

Los signatarios y ratificaciones de la Convención y Protocolo Facultativo pueden consultarse en http://www.un.org/spanish/disabilities/countries.asp?id=578.

30 BOE núm. 96, de 21 de abril de 2008, entrando en vigor, en España, el día 3 de mayo.

31 BOE núm. 97, de 22 de abril de 2008, entrando en vigor, en España, el día 3 de mayo.

32 Al respecto, es preciso recordar que la Ley $1 / 2009$, de 25 de marzo, de reforma de la Ley de 8 de junio de 1957, sobre el Registro Civil, en materia de incapacitaciones, cargos tutelares y administradores de patrimonios protegidos, y de la Ley 41/2003, de 18 de noviembre, sobre protección patrimonial de las personas con discapacidad y de modificación del Código Civil, de la Ley de Enjuiciamiento Civil y de la normativa tributaria con esta finalidad, establece, en su Disposición final $1^{\mathrm{a}}$, que "el Gobierno, en el plazo de seis meses desde la entrada en vigor de esta Ley (la cual tuvo una vacatio legis de 3 meses desde su publicación), remitirá a las Cortes Generales un Proyecto de Ley de reforma de la legislación reguladora de los procedimientos de incapacitación judicial, que pasarán a denominarse procedimientos de modificación de la 
de la que tan sólo es conocida su denominación, "procedimiento de modificación de la capacidad de obrar"333 y de la creación de mecanismos de protección de la persona ajustados al modelo social de discapacidad proclamado por la Convención ONU, los cuales, por su elasticidad y flexibilidad, han de poderse amoldar a todas y cada una de las situaciones de debilidad de una persona, intentando brindarle el apoyo más adecuado a su concreta necesidad y dando siempre espacio al desarrollo de su personalidad, lo que obliga a considerar a la tutela como remedio tuitivo extremo y a proteger a la persona desde una óptica humana y no, exclusivamente, patrimonial $^{34}$.

Sólo ha de importar la persona, su personalidad, su voluntad, sus valores universales de dignidad humana, libertad, igualdad, solidaridad y participación. Nuestras leyes han de impregnarse, pues, del principio

capacidad de obrar, para su adaptación a las previsiones de la Convención Internacional sobre los Derechos de las Personas con Discapacidad, adoptada por Naciones Unidas el 13 de diciembre de 2006", promesa, tras seis años de espera, aún incumplida. Por su parte, la Ley 26/2011, de 1 de agosto, de adaptación normativa a la Convención Internacional sobre los Derechos de las Personas con Discapacidad, en su Disposición adicional $7^{\text {a }}$, rubricada "Adaptación normativa relativa al ejercicio de la capacidad jurídica por las personas con discapacidad, en igualdad de condiciones", contempla que "el Gobierno, en el plazo de un año a partir de la entrada en vigor de esta Ley, remitirá a las Cortes Generales un proyecto de ley de adaptación normativa del ordenamiento jurídico para dar cumplimiento al artículo 12 de la Convención Internacional sobre los Derechos de las Personas con Discapacidad, en lo relativo al ejercicio de la capacidad jurídica por las personas con discapacidad, en igualdad de condiciones que las demás en todos los aspectos de la vida. Dicho proyecto de ley establecerá las modificaciones necesarias en el proceso judicial de determinación de apoyos para la toma libre de decisiones de las personas con discapacidad que los precisen", compromiso, asimismo, incumplido.

33 La expresión "personas con capacidad modificada judicialmente" ya es utilizada por el Real Decreto 1276/2011, de 16 de septiembre, de adaptación normativa a la Convención Internacional sobre los derechos de las personas con discapacidad, por la Ley 20/2011, de 21 de julio, del Registro Civil y por la reciente Ley 15/2015, de 2 de julio, de la jurisdicción voluntaria y la Ley Orgánica 11/2015, de 21 de septiembre, para reforzar la protección de las menores y mujeres con capacidad modificada judicialmente en la interrupción voluntaria del embarazo.

34 Para un mayor estudio, pueden consultarse nuestros trabajos Más allá de la capacidad de entender y querer. Un análisis de la figura italiana de la administración de apoyo y una propuesta de reforma del sistema tuitivo español, Futuex, Olivenza (Badajoz), 2012, galardonado con el Primer Premio de Investigación del Observatorio Estatal de la Discapacidad (2011) (http://www. observatoriodeladiscapacidad.es/informacion/documentos/18181) y "Una propuesta de reforma del sistema tuitivo español: proteger sin incapacitar", en RDP, 2012, núm. 5, septiembre-octubre, págs. 3-40. 
personalista, conforme al cual el rol de los derechos fundamentales es estratégico, de primera importancia.

En pocas palabras, la Convención ONU viene a decirnos que dejemos de una vez de adueñarnos de la vida de las personas con discapacidad y de tomar decisiones por su nombre y cuenta. Satisfacer sus necesidades vitales, conocer sus sentimientos, lograr su bienestar (no sólo económico, sino físico y espiritual), promover su autoestima y, en definitiva, alcanzar su felicidad, poco o nada tiene que ver con su mayor o menor capacidad de entender y querer, sino con su condición de ser humano y, por consiguiente, con el máximo respeto a su yo.

No se trata más que de respetar sus derechos, entendidos éstos no sólo desde el plano jurídico, sino lato sensu: el derecho a la salud, al ocio, a sus inquietudes culturales, a una vida independiente, a la libertad de elegir y de manifestar su consentimiento o disenso (p. ej. en relación a tratamientos médicos u odontológicos, la cesión de sus datos personales, el uso de su imagen, etc.). De este modo, se persigue que la persona sea la única dueña de su propia vida.

\section{EL REAL DECRETO LEGISLATIVO 1/2013, DE 29 DE NOVIEMBRE, POR EL QUE SE APRUEBA EL TEXTO REFUNDIDO DE LA LEY GENERAL DE DERECHOS DE LAS PERSONAS CON DISCAPACIDAD Y DE SU INCLUSIÓN SOCIAL}

2.1 No se trata una Ley General de Discapacidad sino de la refundición de tres leyes en un único texto

Casi llegando a su término el año 2013 y coincidiendo con la conmemoración del Día Internacional de las Personas con discapacidad, se publica el Real Decreto Legislativo 1/2013, de 29 de noviembre, por el que se aprueba el Texto Refundido de la Ley General de derechos de las personas con discapacidad y de su inclusión social en el Boletín Oficial del Estado núm. 289, de 3 de diciembre (con entrada en vigor 
al día siguiente de su publicación) ${ }^{35}$, norma que aborda la tarea de regularización, aclaración y armonización del marco legislativo de los derechos de las personas con discapacidad, más concretamente, de tres leyes: la Ley 13/1982, de 7 de abril, de integración social de las personas con discapacidad (LISMI), la Ley 51/2003, de 2 de diciembre, de igualdad de oportunidades, no discriminación y accesibilidad universal de las personas con discapacidad (LIONDAU) y la Ley 49/2007, de 26 de diciembre, por la que se establece el régimen de infracciones y sanciones en materia de igualdad de oportunidades, no discriminación y accesibilidad universal de las personas con discapacidad (LISMID), las cuales, resultan derogadas por integrarse en el Texto Refundido.

Precisamente, el Decreto-Legislativo no es más que el cumplimiento, por parte del Ejecutivo, del mandato de la Disposición final $2^{a}$ de la Ley 26/2011, de 1 de agosto, de adaptación normativa a la Convención Internacional sobre los derechos de las personas con discapacidad, en la redacción dada por la Disposición final $5^{\mathrm{a}}$ de la Ley 12/2012, de 26 de diciembre, de medidas urgentes de liberalización del comercio y de determinados servicios, que establecía como finales de diciembre 2013 el plazo de la delegación legislativa ${ }^{36}$.

Sin duda alguna, hemos de comenzar por afirmar que el título es mucho más ambicioso que su contenido, puesto que denominándose "Texto Refundido de la Ley General de derechos de las personas con discapacidad y de su inclusión social", lo primero que ha de advertirse

35 El Dictamen 1183/2013 del Consejo de Estado sobre el proyecto de Real Decreto Legislativo por el que se aprueba el Texto Refundido de la Ley General de Derechos de las Personas con Discapacidad y de su Inclusión Social puede consultarse en http://www.boe.es/buscar/doc.php? id=CE-D-2013-1183.

36 La redacción recibida por la Ley 12/2012 es, en concreto, la siguiente: "El Gobierno elaborará y aprobará antes del 31 de diciembre de 2013 y previa consulta al Consejo Nacional de la Discapacidad, un Texto Refundido en el que se regularicen, aclaren y armonicen la Ley 13/1982, de 7 de abril, de integración social de los minusválidos, la Ley 51/2003, de 2 de diciembre, de igualdad de oportunidades, no discriminación y accesibilidad universal de las personas con discapacidad y la Ley 49/2007, de 26 de diciembre, de infracciones y sanciones en materia de igualdad de oportunidades, no discriminación y accesibilidad universal de las personas con discapacidad". 
es que no se trata de una norma "General”, pues se limita a refundir las tres leyes antes citadas en un solo cuerpo jurídico, no abarcando, por consiguiente, todo el marco legislativo de la discapacidad. Dicho de otro modo, no unifica toda la normativa existente en la materia.

2.2 Los límites de la delegación legislativa y novedades más destacables de la Ley

La norma consta de ciento cinco artículos, estructurados en un título preliminar y tres títulos más (con una estructura muy similar a la de la Convención ONU), once Disposiciones Adicionales, una Disposición Transitoria y tres Disposiciones Finales.

Resultándonos imposible aquí realizar un análisis exhaustivo de la norma, nos limitaremos a apuntar las novedades más destacadas de la misma.

Con carácter previo conviene recordar que el art. $82.5 \mathrm{CE}^{37}$ distingue dos modalidades de autorización a la refundición: mera formulación de un texto único o regularización, aclaración y armonización de los textos legales que han de ser refundidos. En esta segunda modalidad, se atribuye al Gobierno una operación técnica y no creadora, esto es, la delegación legislativa contenida en la autorización al Ejecutivo para refundir los textos legales no permite introducir innovaciones en el Ordenamiento jurídico pero sí llevar a cabo una aclaración suficiente del sentido poco preciso de las normas refundidas, que facilita el mejor encaje de las mismas con otras que les afectan, también objeto de la delegación legislativa.

La cuestión de los límites de la delegación legislativa y del eventual exceso en la actividad refundidora derivada de una delegación legislativa (ultra vires) por parte del Gobierno reviste sumo interés y

37 Art. 82-5 CE: "La autorización para refundir textos legales determinará el ámbito normativo a que se refiere el contenido de la delegación, especificando si se circunscribe a la mera formulación de un texto único o si se incluye la de regularizar, aclarar y armonizar los textos legales que han de ser refundidos". 
el Tribunal Constitucional ya ha tenido ocasión de tratarla en diversas ocasiones. Conforme a la doctrina constitucional sobre los límites al ejercicio por parte del Gobierno de la delegación legislativa (entre otras, la STC 13/1992, de 6 de febrero ${ }^{38}$, la STC 205/1993, de 17 de junio ${ }^{39}$ y STC 166/2007, de 4 de julio ${ }^{40}$ ), en el caso de refundición de varios textos legales la capacidad de innovación del Gobierno se limita a la labor de regularización, aclaración y armonización de textos legales. Dicha labor refundidora permite, incluso, "introducir normas adicionales y complementarias a las que son objeto estrictamente de la refundición, siempre que sea necesario colmar lagunas, precisar su sentido o, en fin, lograr la coherencia y sistemática del único texto refundido", como señala el Tribunal Constitucional en su ya citada STC 13/1992, de 6 de febrero (FJ. 16) y en la STC 166/2007, de 4 de julio, según la cual se entiende que la facultad añadida en la autorización para refundir "permite la explicitación de normas complementarias a las que son objeto de refundición, con el fin de colmar lagunas y, en todo caso, habilita para llevar a cabo una depuración técnica de los textos legales a refundir, aclarando y armonizando preceptos y eliminando discordancias y antinomias detectadas en la regulación precedente, para lograr así que el texto refundido resulte coherente y sistemático" (FJ. 8).

Abordando ya las novedades más destacadas del Texto Refundido, el art. 2, dedicado a las definiciones, contiene la de discapacidad: “a) Discapacidad: es una situación que resulta de la interacción entre las personas con deficiencias previsiblemente permanentes y cualquier tipo de barreras que limiten o impidan su participación plena y efectiva en la sociedad, en igualdad de condiciones con las demás".

Importantes son también las definiciones de discriminación directa ("es la situación en que se encuentra una persona con discapacidad cuando es tratada de manera menos favorable que otra en situación

\footnotetext{
38 RTC 1992, 13.

39 RTC 1993, 205.

40 RTC 2007, 166.
} 
análoga por motivo de o por razón de su discapacidad"), indirecta ("existe cuando una disposición legal o reglamentaria, una cláusula convencional o contractual, un pacto individual, una decisión unilateral o un criterio o práctica, o bien un entorno, producto o servicio, aparentemente neutros, puedan ocasionar una desventaja particular a una persona respecto de otras por motivo de o por razón de discapacidad, siempre que objetivamente no respondan a una finalidad legítima y que los medios para la consecución de esta finalidad no sean adecuados y necesarios"), por asociación ("existe cuando una persona o grupo en que se integra es objeto de un trato discriminatorio debido a su relación con otra por motivo o por razón de discapacidad") ${ }^{41}$ y acoso ("es toda conducta no deseada relacionada con la discapacidad de una persona, que tenga como objetivo o consecuencia atentar contra su dignidad o crear un entorno intimidatorio, hostil, degradante, humillante u ofensivo") ex art. 4, letras c), d), e) y f).

También resulta de interés conocer qué entiende la nueva norma por "personas con discapacidad". En este sentido, el art. 4.1 establece que "son personas con discapacidad aquellas que presentan deficiencias físicas, mentales, intelectuales o sensoriales, previsiblemente permanentes que, al interactuar con diversas barreras, puedan impedir su participación plena y efectiva en la sociedad, en igualdad de condiciones con los demás", añadiendo en su n² 2: "además de lo establecido en el apartado anterior, y a todos los efectos, tendrán

41 Al Consejo de Estado le plantea dudas el término "discriminación por asociación", tal y como expresa en su Dictamen: "...mayores dificultades ofrecen otras incorporaciones en el seno de la refundición proyectada como es el caso del término "discriminación por asociación" (la circunstancia personal o social que motiva el trato peyorativo no concurre en la persona discapacitada, sino en alguno de sus allegados o persona "asociada") que la propia memoria reconoce que constituye una novedad. Aunque, en efecto, este concepto viene siendo habitualmente empleado (con distinta terminología: "discriminación por asociación", "discriminación por vinculación", ...) sobre todo a partir de la Sentencia de 17 de julio de 2008 del Tribunal de Justicia de la Unión Europea, en el asunto C-303/06, Coleman v. Atridge, donde se reconoce la existencia de este tipo de discriminación, sin embargo, el Consejo de Estado considera que el Gobierno, en su labor de refundición, debería seguir más de cerca los textos legales que se refunden, evitando innovaciones que, en todo caso, podrían ser objeto de una posterior iniciativa legislativa como más adelante se indicará". 
la consideración de personas con discapacidad aquellas a quienes se les haya reconocido un grado de discapacidad igual o superior al 33 por ciento. Se considerará que presentan una discapacidad en grado igual o superior al 33 por ciento los pensionistas de la Seguridad Social que tengan reconocida una pensión de incapacidad permanente en el grado de total, absoluta o gran invalidez, y a los pensionistas de clases pasivas que tengan reconocida una pensión de jubilación o de retiro por incapacidad permanente para el servicio o inutilidad".

Así las cosas, el concepto de discapacidad empleado por el Texto Refundido, inexistente en las Leyes objeto de refundición, es acorde con los mandatos de la Convención $\mathrm{ONU}^{42}$, destacándose la asimilación a todos los efectos el reconocimiento del grado de discapacidad con el de la pensión de incapacidad permanente en el grado de total, absoluta o gran invalidez, la pensión de clases pasivas que tengan reconocida una pensión de jubilación o de retiro por incapacidad permanente para el servicio o inutilidad ${ }^{43}$.

En su art. 6 dispone, conforme a los postulados de la Convención ONU (Preámbulo, letra $n$ y arts. 3 y 12.4), que "el ejercicio de los

42 Según el Dictamen del Consejo de Estado, "entrando en el examen del texto proyectado, por lo que se refiere al concepto de "discapacidad", no se recoge expresamente en ninguno de los textos refundidos, sino que, como se ha indicado, se encuentra en el artículo 1 de la Convención. Ahora bien, a juicio del Consejo de Estado no resulta inadecuada la inclusión de esta definición ("discapacidad") pues, además de resultar de los propios principios y garantías recogidos en las normas objeto de refundición, en el propio Acuerdo de Consejo de Ministros de 30 de marzo de 2010, que aprobó el Informe sobre las medidas necesarias para la adaptación de la legislación española a la Convención de la ONU sobre los derechos de las personas con discapacidad, se aclara que (...) "Los principios de la Convención y los derechos que en ella se reconocen no difieren en esencia de los recogidos en nuestra LIONDAU (norma que ahora se refunde). Sin embargo, comportan un cambio en el concepto de discapacidad, que supone pasar de considerar a la discapacidad como una preocupación en materia de bienestar social, a conceptuarla como una cuestión de derechos humanos; lo que obliga a modificar el enfoque de nuestra normativa interna".

43 Recuérdese que, en el régimen de propiedad horizontal, el art. 1.3 de la Ley 15/1995, de 30 de mayo, sobre límites del dominio sobre inmuebles para eliminar barreras arquitectónicas a las personas con discapacidad, dispone: "3. Los derechos que esta Ley reconoce a las personas con minusvalía física podrán ejercitarse por los mayores de setenta años sin que sea necesario que acrediten su discapacidad con certificado de minusvalía", de modo que, a efectos de la Ley de Propiedad Horizontal, la persona con 70 o más años queda plenamente equiparada a la persona con discapacidad. 
derechos de las personas con discapacidad se realizará de acuerdo con el principio de libertad en la toma de decisiones" y que "las personas con discapacidad tienen derecho a la libre toma de decisiones, para lo cual la información y el consentimiento deberán efectuarse en formatos adecuados y de acuerdo con las circunstancias personales, siguiendo las reglas marcadas por el principio de diseño universal o diseño para todas las personas, de manera que les resulten accesibles y comprensibles".

En cuanto a los equipos multiprofesionales de calificación y reconocimiento del grado de discapacidad, además de valorar las limitaciones y barreras a las que se enfrentan a las personas con discapacidad, valorarán también sus capacidades y habilidades para las cuales necesitan apoyo (art. $12.3^{\circ}$ a.).

Respecto del derecho a la educación, se asegura un sistema educativo inclusivo (art. 16), si bien la Ley General ha de ser respetuosa con el marco de la Ley Orgánica 2/2006, de 3 de mayo, de Educación.

En relación al derecho al trabajo, el art. $35.6^{\circ}$ y $7^{\circ}$ del Texto Refundido contempla el acoso por razón de la discapacidad y contempla como acto discriminatorio la orden genérica de discriminar por razón de la discapacidad.

En el ámbito del empleo, la norma clasifica los tipos de empleo a través de los que las personas con discapacidad pueden ejercer su derecho al trabajo: empleo (con apoyo en el mercado) ordinario de trabajo, de las empresas y administraciones públicas, incluidos los servicios de empleo con apoyo (RD 870/2007), incluyendo la cuota del $2 \%$ en empresas de más de 50 trabajadores, y, en su caso, las medidas alternativas (RD 364/2005); empleo protegido (apoyo a la inserción) en centros especiales de empleo (que figuren inscritos como tales en el Registro correspondiente) y enclaves laborales (RD 290/2004) y empleo autónomo (apoyo al autoempleo) con las medidas previstas en la Ley 11/2013, de 26 de julio, de medidas de apoyo al emprendedor y de estímulo del crecimiento y de la creación de empleo (Real Decreto-ley 4/2013, de 22 de febrero). 
Al respecto, ha de tenerse presente que, según la Base de Datos Estatal de las Personas con Discapacidad,1.450.800 personas de edades comprendidas entre los 16 y los 64 años y residentes en hogares familiares tenía certificado de discapacidad en 2012 (un 4,8\% de la población total española en edad laboral y un incremento del 15\% respecto a 2011) y que la tasa de paro para el colectivo fue del 33,1\% en 2012, 8,1 puntos superior a la de la población sin discapacidad, según la última Encuesta de Población Activa y de la Base Estatal de Personas con Discapacidad, "El empleo de las personas con discapacidad"44.

La norma objeto de nuestra breve glosa establece nuevos plazos máximos de exigibilidad para las condiciones básicas de la accesibilidad y no discriminación ya previstos en la Ley 51/2003, especialmente, los de para el acceso y utilización de los bienes y servicios a disposición del público por las personas con discapacidad, cuyos plazos oscilan del 2015 al 2017 (Disp. Adic. 3a).

\section{Conclusion}

La norma ha de recibir, sin duda, una primera valoración positiva por el gran avance que implica, si bien con matices que iremos desarrollando.

La coexistencia durante todos estos años de tres Leyes reguladoras de distintos aspectos de la discapacidad, todas ellas de innegable relevancia pero muy dispares y pertenecientes a momentos históricos distintos, a lo que se suma la enorme evolución que ha experimentado la materia, muy especialmente, a partir del fuerte impulso a la misma por parte de la Convención ONU. El enfoque de la discapacidad ha cambiado sustancialmente, lo cual ha hecho necesario un esfuerzo para armonizar, aclarar y actualizar la normativa existente en el ámbito de los

\footnotetext{
44 Nota de prensa del INE de 9 de diciembre de 2012, la cual puede consultarse en http://www.ine. es/prensa/np821.pdf
} 
derechos de las personas con discapacidad, a lo que responde, en un contexto maduro como el actual, la Ley.

De este modo, el Texto Refundido intenta aminorar y clarificar la dispersión normativa en el ámbito de los derechos de las personas con discapacidad, lo que permite disminuir las eventuales dudas interpretativas en la aplicación de las tres normas, revirtiendo, ello, en una mayor seguridad jurídica.

La Ley General, además de abordar una necesaria renovación terminológica ${ }^{45}$ más adecuada a los postulados de la Convención ONU, subraya, siguiendo la estela del citado Tratado Internacional, que las personas con discapacidad son sujetos titulares de derechos y que los poderes públicos están obligados a garantizar que el ejercicio de tales derechos sea pleno y efectivo, superándose, de este modo, el modelo asistencial conocido hasta épocas muy recientes.

La norma, asimismo, reconoce explícitamente el principio de autonomía y libertad en la toma de decisiones.

No obstante, comenzamos con los ya anunciados matices de nuestro juicio positivo a la Ley.

Permítasenos mostrar nuestra gran insatisfacción, puesto que, de un lado, la Ley General no elimina, ni mucho menos, la dispersión normativa existente en materia de discapacidad, puesto que tan sólo ha refundido tres leyes, dejando atrás las ambigüedades y contradicciones de otros textos normativos, como las de la Ley 41/2003, de 18 de noviembre, de protección patrimonial de las personas con discapacidad y de modificación del Código civil, de la Ley de Enjuiciamiento civil y de la normativa tributaria, o las de la Ley 14/2007, de 3 de julio, de

45 Como manteníamos en nuestro trabajo La dignidad de las personas con discapacidad. Logros y retos jurídicos, (VIVAS TESÓN, 2010, p. 29) "no se trata de utilizar un lenguaje políticamente correcto, tan de moda en nuestros días, sino de construir pensamiento y cultura a través de la palabra, superando viejos prejuicios y estereotipos que, tal vez, sin ser siquiera conscientes de ello (de ahí, esta llamada a la reflexión), aparecen en el lenguaje de uso común en nuestra vida cotidiana". 
Investigación Biomédica ${ }^{46}$, a día de hoy, inaceptables. Ello provoca que el concepto de "discapacidad" no sea único, siendo distinto (más o menos restringido) según la norma de que se trate (siempre que ésta no haya sido refundida en la Ley General).

De otro lado, si bien es digno de un largo y sonoro aplauso el reconocimiento expreso del principio de autonomía y libertad en la toma de decisiones, no llegamos a comprender cómo no se ha cumplido ya con la promesa de reformar el procedimiento de incapacidad judicial (tan sólo ha sufrido un mínimo retoque terminológico) y el sistema tuitivo español mediante la creación de mecanismos de protección de la persona ajustados al modelo social de discapacidad proclamado por la Convención ONU, convirtiendo la tutela en la última medida de guarda e intentando proteger a la persona humana y sus derechos, no sus bienes.

Sin duda alguna, se trata ésta de una reforma legislativa de mayor alcance y complejidad, pues afecta a la capacidad jurídica de la persona, pero si no se acomete (lo cual, a estas alturas, consideramos inexplicable $)^{47}$, el reconocimiento expreso de la autonomía y libertad en la

$46 \quad 47$ Hemos tenido ocasión de analizarlas en algunos de nuestros trabajos, entre otros: "Una aproximación al patrimonio protegido a favor de la persona con discapacidad", en Revista de Derecho de la Universidad Austral de Chile, v. 22, nº. 1, julio 2009, págs. 55-76; La dignidad de las personas con discapacidad: logros y retos jurídicos, Difusión jurídica, Madrid, 2010; "La solemnidad formal del patrimonio protegido a favor de la persona con discapacidad", en Revista Crítica de Derecho Inmobiliario, núm. 718, marzo-abril, 2010, págs. 585-618; "La autotutela en Derecho Comparado: un mecanismo de autoprotección en previsión de una futura incapacitación judicial", en Revista de Derecho de Familia y de las Personas, Año 2, número 2, Marzo 2010, págs. 207-214, "Bioinvestigación, biobancos y consentimiento informado del sujeto fuente vulnerable", en Diario La Ley, $n^{\circ} 7911$ de 27 de julio de 2012, págs. 1-12; La figura del patrimonio especialmente protegido a favor de una persona con discapacidad: balance de sus nueve años de vigencia", en Cuestiones actuales de Derecho Patrimonial desde una perspectiva ítalo-española, MURGA FERNANDEZ y TOMÁS TOMÁS (Coords.), Tirant lo Blanch, Valencia, 2013, págs. 53-71; "Discapacidad y consentimiento (o disenso) informado: el derecho de la persona a ser dueña de su propia vida", en Revista Jurídica del Notariado, núm. 82 abril-junio 2013, págs. 483-516; "Bioresearch, biobanks and informed consent from vulnerable donors in Spanish Law", en Europa e Diritto Privato, 2013, fasc. 4, págs. 1068-1095; "Consentimiento del adulto frágil al tratamiento de muestras biológicas y datos genéticos con fines de investigación biomédica: comparación entre el Derecho Español e Italiano", en Revista de Derecho y Genoma Humano, 2014, núm. 40, págs. 95-130 y "La percepción jurídica de la infancia, adolescencia y discapacidad en tiempos de crisis. Una revisión crítica del actual escenario normativo", en Crónica Jurídica Hispalense, núm. 12, 2014, págs. 67-106.

$47 \quad$ En nuestro trabajo ya citado Más allá de la capacidad de entender y querer. Un análisis de la figura italiana de la administración de apoyo y una propuesta de reforma del sistema tuitivo español, Futuex, Olivenza (Badajoz), 2012 contenemos algunas propuestas de reforma del sistema de protección de las personas no autónomas. 
toma de decisiones no es más que un (bonito) papel mojado si nuestros jueces y tribunales, aplicadores del Derecho civil vigente, siguen en sus sentencias privando a las personas de su libertad hasta límites extremos como la negación de su derecho de sufragio activo.

\section{Referencia}

GANZENMÜLLER ROIG, Carlos. Ministério Fiscal. De la efectiva aplicación de la Convención de Naciones Unidas sobre los derechos de las personas con discapacidad y sus efectos en el Derecho interno. 2009. Disponível em: <https://www.fiscal.es/fiscal/PA WebApp_SGNTJ_NFIS/descarga/GANZENMULLECONVENCION\%20 ONU\%20PCD\%20VERSION\%20DEFINITIVA.pdf?idFile=b247f196891b-4705-8686-4b3ed635f5d8> Acesso em: 02 ago. 2015.

INSTITUTO NACIONAL DE ESTADÍSTICA. Encuesta de discapacidad, autonomia personal y situaciones de dependencia. 2008. Disponível em: <http://www.ine.es/prensa/np524.pdf>. Acesso em: 04 jul. 2015

MÁRQUEZ CARRASCO, Carmen. Logros y desafíos en el 60 aniversario de la Declaración Universal de Derechos Humanos. Deusto: Bilbao, 2008.

MINISTÉRIO FISCAL. Jornadas de Fiscales Especializados en la Protección de las Personas con Discapacidad y Tutelas. 2009. Disponível em: <https://www.fiscal.es/fiscal/PA_WebApp_SGNTJ_NFIS/ descarga/CONCLUSIONES\%20JORNADAS\%20DE\%20FISCALES. pdf?idFile=6433245e-22f9-4531-953f-24f39027a998>. Acesso em: 08 jul. 2015

VIVAS TESÓN, Inmaculada. La dignidad de las personas con discapacidad. Logros y retos jurídicos. Madrid, Revista Difusión jurídica, 2010, n. 15, p. 247-251.

Recebido em: 01/12/2015

Aprovado em: 12/12/2015 